\title{
Current Status of Nuclear Waste Management (and Disposal) in the United States
}

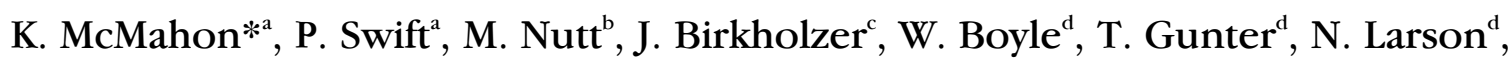 \\ R. MacKinnon ${ }^{a}$, and K. Sorenson ${ }^{a}$ \\ ${ }^{\text {a }}$ Sandia National Laboratories, Albuquerque, NM, USA \\ ${ }^{\mathrm{b}}$ Argonne National Laboratory, Argonne, IL, USA \\ ${ }^{\mathrm{c}}$ Lawrence Berkeley National Laboratory, Berkeley, CA, USA \\ ${ }^{d}$ U.S. Department of Energy, Las Vegas, NV, USA
}

Abstract : The United States Department of Energy (US DOE) is conducting research and development (R\&D) activities under the Used Fuel Disposition Campaign (UFDC) to support storage, transportation, and disposal of used nuclear fuel (UNF) and wastes generated by existing and future nuclear fuel cycles. $R \& D$ activities are ongoing at nine national laboratories, and are divided into storage, transportation and disposal. Storage $R \& D$ focuses on closing technical gaps related to extended storage of UNF. Transportation R\&D focuses on ensuring transportability of UNF following extended storage, and addressing data gaps regarding nuclear fuel integrity, retrievability, and demonstration of subcriticality. Disposal $R \& D$ focuses on identifying geologic disposal options and addressing technical challenges for generic disposal concepts in mined repositories in salt, clay/shale, and granitic rocks, and deep borehole disposal. UFDC R\&D goals include increasing confidence in the robustness of generic disposal concepts, reducing generic sources of uncertainty that may impact the viability of disposal concepts, and developing science and engineering tools to support the selection, characterization, and licensing of a repository. The US DOE has also initiated activities in the Nuclear Fuel Storage and Transportation (NFST) Planning Project to facilitate the development of an interim storage facility and to support transportation infrastructure in the near term.

Keywords: US Nuclear waste management, Used fuel disposition campaign, Storage, Transportation, Disposal

\section{INTRODUCTION}

In June 2009, the United States Department of Energy Office of Nuclear Energy (US DOE-NE) initiated planning for a research and development (R\&D) program, the "Used Fuel Disposition Campaign," (UFDC) within its Office of Fuel Cycle Technologies. The mission of the UFDC, essentially unchanged from its first definition in the fall of 2009, is to identify alternatives and conduct scientific research and technology development to enable storage, transportation, and disposal of used nuclear fuel (UNF) and wastes generated by existing and future nuclear fuel cycles. R\&D within the UFDC is

Received : July 25, 2013 • Revised : August 11, 2013 • Approved : September 13, 2013

*Corresponding Author : Kevin McMahon

Sandia National Laboratories, Albuquerque, NM

Tel : +1-505-844-5184 E-mail : kamcmah@sandia.gov

P.O. Box 5800, Albuquerque, NM 87185, U.S.A conducted at nine U.S. national laboratories (Argonne National Lab, Idaho National Lab, Los Alamos National Lab, Lawrence Berkeley National Lab, Lawrence Livermore National Lab, Oak Ridge National Lab, Pacific Northwest National Lab, Savannah River National Lab and Sandia National Laboratories) and supports the larger two-part mission of the DOE-NE Fuel Cycle R\&D (FCR\&D) Program, developing used nuclear fuel management strategies and technologies to help meet the federal government's responsibility to manage and dispose of the nation's commercial used nuclear fuel and high-level radioactive waste and developing sustainable fuel cycle technologies and options that improve resource utilization and energy generation, reduce waste generation, enhance safety, and limit proliferation risk. The overall objectives of the DOE-NE research and development program are outlined in the April 2010 "Nuclear Energy Research and Development Roadmap Report to Congress." [1]

In January 2012, the Blue Ribbon Commission on 
America's Nuclear Future (BRC) published its Report to the Secretary of Energy [2]. Among the recommendations from the BRC specific to transportation, storage and disposal was the statement that the BRC ".... believes the general direction of the current DOE research and development $(R \& D)$ program is appropriate..." and generally endorsed the approaches undertaken by the UFDC to continue $\mathrm{R} \& \mathrm{D}$ on generic nuclear facility sites.

In January 2013, the DOE published Strategy for the Management and Disposal of Used Nuclear Fuel and High-Level Radioactive Waste [3], outlining a strategy for licensing and operating a pilot interim storage facility by 2021 , operating a larger interim storage facility by 2025 , and facilitating the availability of a geologic repository by 2048. R\&D conducted within the UFDC supports this strategy.

\section{USED FUEL DISPOSITION CAMPAIGN OBJECTIVES}

The safe management and disposition of UNF and/or high-level radioactive waste is a fundamental aspect of the nuclear fuel cycle. The United States currently implements a once-through fuel cycle where UNF is stored on-site in either wet pools or in dry storage systems with ultimate disposal envisioned to be in a deep mined geologic repository. Multiple disposal strategies and extended interim storage both at reactor sites and in centralized interim storage facilities are being considered. In addition, the FCR\&D Program is investigating alternatives to the once-through fuel cycle and the UFDC will help provide a sound technical basis for managing radioactive wastes from any future nuclear fuel-cycle. Regardless of the fuel cycle chosen, future disposition paths will involve both the storing of radioactive material for some period of time and the ultimate disposal of radioactive waste.

The storage and transportation of UNF has a stable regulatory basis, and is technically mature, and operationally safe. However, two recent factors have precipitated the current DOE-NE R\&D investments. First, there is a likely need for existing storage licenses to be extended beyond their current regulatory time limits. Second, the utility industry has been maximizing plant efficiencies which have resulted in markedly higher average burnups for the fuel now entering storage. Data on used fuel behavior and characteristics will be useful to support the demonstration of safe storage over long periods of time, as well as safe transportation subsequent to storage. For high burnup fuels, data as well as modeling and simulation will help demonstrate fuel behavior and characteristics during extended storage and transportation. While the near-term focus of the FCR\&D Program is on existing UNF, wastes from alternative fuel cycle technologies will also be addressed. Research will identify and develop practical storage systems for these materials, leveraging the experience gained for developing LWR used fuel storage systems.

The disposal of radioactive waste of all classifications (low-, intermediate-, high-level radioactive waste, and UNF) has been investigated world-wide since the inception of nuclear power. While significant progress has been made regarding disposal options, implementation of disposal facilities for UNF and radioactive waste remains challenging. Experience both in the US and other nations has illustrated the challenges of siting, characterizing, designing, and licensing a geologic repository. Progress in the U.S. has been demonstrated by the deployment of near-surface disposal facilities for low-level waste and the Waste Isolation Pilot Plant (WIPP) for the disposal of defense-related transuranic wastes. However, the capacity for disposing low-level wastes is limited, final disposal pathways for Greater Than Class C low-level waste (which is essentially intermediate level waste) have yet to be identified, and the disposal of UNF and high-level radioactive waste has not been implemented.

Recognizing that the current system for managing nuclear waste is viable for several decades, the UFDC has established five near-term objectives and four longterm objectives.

\subsection{Near-Term Objectives}

- Provide technical expertise to inform policy regarding the management of UNF and radioactive waste that would be generated under existing and potential future nuclear fuel cycles.

- Develop a comprehensive understanding of the current technical bases for storing UNF and high-level radioactive waste to identify long-term research and development opportunities.

- Develop a technical basis for the retrievability and transportation of high-burnup UNF.

- Develop a comprehensive understanding of the current technical bases for disposing UNF, low-level radioactive waste, and high-level radioactive waste in a range of potential disposal environments to identify long-term research and development opportunities.

- Continue model development, confirmed by experiments, for the evaluation of disposal system performance with a variety of generic disposal system concepts and environments.

\subsection{Long-Term Objectives}

- Develop a fundamental understanding of the performance of potential storage system concepts over many decades for a variety of UNF types and 
radioactive waste forms based on simulations and experiments.

- Initiate long-term storage strategies through a smallscale demonstration project that incorporates the technologies identified and developed from the near-term storage objectives.

- Develop a fundamental understanding of disposal system performance in a range of environments for potential wastes that could arise from future nuclear fuel cycle alternatives through theory, simulation, testing, and experimentation.

- Develop computational modeling capability, confirmed by experiments, for the performance of storage, transportation, and disposal options for a range of fuel cycle alternatives.

\section{KEY TECHNICAL CHALLENGES}

\subsection{Storage}

Used LWR fuel is currently being safely and securely stored in the U.S., primarily at the locations where it was generated. It is initially stored in wet used fuel pools, but as these pools fill to capacity, the used fuel is transferred to dry canisters that are stored on-site. UNF is also transferred from wet pools to dry storage systems when a nuclear power plant is decommissioned, but at present the used fuel remains at the site of the reactor.

High-level radioactive waste, including both liquid wastes from reprocessing of UNF and solid waste forms, primarily vitrified borosilicate glass generated from liquid wastes, is currently stored in the U.S. at facilities managed by the DOE Office of Environmental Management.

Existing storage systems provide radiation shielding and protection for both workers and the public, and dissipate heat emanating from radioactive decay of the waste. Security is provided both by physical barriers and the protective force present at the sites.

Neither wet nor dry storage systems offer a permanent solution for managing UNF or high-level radioactive waste. Rather, they are designed to be temporary with plans for ultimate removal of the material and subsequent disposition (i.e., disposal). The unavailability of disposition options, such as a permanent disposal facility, has resulted in the potential need for an extended storage period. Dry used fuel storage systems are typically licensed by the US Nuclear Regulatory Commission (NRC) for a 40-year period, with the possibility of a 40year license renewal allowing for up to 80 years of operation under current regulations.

Current practice provides for safe and secure storage of UNF at existing facilities, and is a reasonable approach based on current economics, a stable regulatory environment, and sufficient land space to expand the on-site storage footprint, as needed. From a longer term strategic perspective, several considerations are relevant to the design of an $R \& D$ program:

- As UNF continues to be stockpiled in long-term storage, on-site storage space will become limited and, consistent with the DOE's Strategy [3], there may be benefits from consolidated storage of UNF at one or more locations.

- The higher burnup UNF that is typical of current industry practice may require additional assessments to verify its behavior during extended storage.

- Validation requirements for UNF integrity for transportation after long-term storage may need to be developed.

- Experiments to obtain used fuel cladding material property data are inherently expensive and complex.

The 5- and 10-year UFDC, goals for storage are structured to address these issues so that all fuel cycle material will continue to be stored in a safe and secure manner and in a way that will be adaptable to selected disposal paths.

\subsection{Transportation}

Significant R\&D and operational experience related to the transportation of LWR used fuels has been accumulated. However, higher burnup fuels and advanced fuels developed as part of future fuel cycle options will likely require development of an associated materials properties database and may require new technologies to support their transportation. The following are the $R \& D$ topics associated with safe and secure transportation activities:

Material Property Understanding. The safety of extended storage and subsequent transportation of UNF will be verified through experimental data collection, associated modeling and simulation, and confirmatory demonstration. In particular, material property data will be focused on the cladding of high burnup UNF.

Cladding Integrity Investigations. There is a small body of data associated with the performance of high burnup fuels during transportation. Work is being conducted to investigate the impact on strength and ductility that burnup has on the fuel cladding and its performance during transport.

Over-the-Road Testing. There are currently gaps in the understanding of forces that used fuel experiences during transport. Planning is underway to conduct over-theroad tests on instrumented dummy assemblies to ascertain actual loads that the fuel sees during transport. This loading information, coupled with cladding integrity investigations, will allow quantification of fuel response during transport.

Secure Transportation. There is currently no commer- 
cial capability in the U.S. to transport large quantities of Category I and II nuclear and radioactive materials, which require enhanced security. The DOE Safeguards Trailer (SGT) has been used on some shipments (e.g., Eurofab mixed oxide [MOX] fuel) in the U.S. However, the SGT should not be relied on for large-scale commercial transport operations that could be required for shipments of Category I and II materials associated with extended storage scenarios. Work is being conducted to identify and evaluate security issues associated with extended storage of used fuel.

\subsection{Disposal}

Permanent disposal of UNF and radioactive waste is only acceptable if sufficient isolation can be provided so that the risk of future radiation exposure from the waste meets regulatory requirements.

A variety of concepts for disposing of radioactive waste have been investigated extensively world-wide for decades, since the inception of nuclear energy. These concepts address the disposal of low-level waste in shallow land burial facilities, disposal of intermediate- level waste in intermediate-depth facilities, and disposal of high-level radioactive waste and UNF in deep mined geologic repositories. In some cases, disposal facilities have been sited, licensed/permitted, constructed, and are in operation. In other cases, the siting-licensing-construction- operation process is underway. Other disposal concepts, such as deep borehole disposal, have also been considered and investigated, although not as in-depth or as extensively as mined repositories.

Safe disposal of radioactive wastes is accomplished by isolating the waste for sufficiently long time periods. Isolation is achieved through a combination of engineered and natural barriers (e.g., robust waste packages and very slow radionuclide transport through the surrounding rocks), essentially resulting in no radiological risk in the surrounding biosphere for many thousands of years when these barriers perform as expected. Over the very long time periods necessary to isolate the wastes, the engineered barriers may degrade allowing radionuclides still present in the waste to be released at low rates into the natural system. The natural system will act to reduce and delay the subsequent migration of these released radionuclides to the accessible environment to levels, established in regulatory standards, typically well below naturally occurring levels of background radiation. Understanding when radionuclides may begin to be released from the disposal system, the rate that they may be released, and how they might migrate through the natural system are primary factors in demonstrating the safety of a disposal system concept.

Geologic disposal concepts are typically complex systems with physical and chemical couplings between the disposed waste, engineered barrier materials, and the natural system. The long-term radionuclide isolation capabilities and characteristics of a waste disposal environment are dependent on the details of the site and the form and contents of the wastes to be disposed. Disposal facilities can be geographically large and the distance over which materials could potentially migrate can be long. Estimates of how disposal systems could evolve over very large time scales, considering chemical and physical couplings and large length scales, remain uncertain. Reducing this uncertainty, quantifying this uncertainty, and propagating this uncertainty through safety assessments have been and continue to be challenges in demonstrating the viability of geologic disposal.

Due to the complexity of the disposal systems and the long time frames involved, precise predictions of repository performance are not possible, and uncertainty must be acknowledged in the decision-making process. However, R\&D can and should be undertaken to support evaluations of a regulatory finding of a reasonable expectation that a disposal system is appropriately protective of public health and safety. Research and development focuses on gathering sufficient data (laboratory and field) and developing computational models for evaluating and demonstrating long-term disposal system performance.

\section{USED FUEL DISPOSITION CAMPAIGN ACTIVITIES}

The UFDC is organized into three management groups:

- The Crosscutting (CX) group consists of activities that are campaign wide and may affect storage, transportation and disposal.

- The Storage and Transportation (ST) research and development group consists of activities specifically associated with the storage and transportation of radioactive wastes.

- The Disposal Research (DR) group consists of activities specifically associated with the disposal of radioactive wastes.

A summary of the activities in each of the campaign management groups follows.

CX-Campaign Management and Integration supports campaign management and integration activities. Specific responsibilities include ensuring technical R\&D work throughout the campaign is of high quality and meets programmatic requirements; as well as integrating $R \& D$ activities across the campaign and with other campaigns and industry participants. 
CX-Storage, Transportation and Disposal Interface Analysis obtains both qualitative and quantitative information regarding the back-end of the nuclear fuel cycle (storage, transportation, and disposal.)

CX-International coordinates and facilitates international collaborative activities for the UFDC.

ST-Field Demonstration plans and deploys a storage demonstration that will contribute to the understanding of component material degradation issues important to safety. This effort will be conducted in close collaboration with industry and the NRC. This work specifically addresses potential paths to fielding a demonstration platform based on input from industry, the BRC recommendations [2], the DOE's strategy in response to the $\mathrm{BRC}$ recommendations [3], Congressional guidance, and other inputs as applicable.

ST-Storage and Transportation Experiments conducts separate effects tests and small-scale tests that address issues including, delayed hydride cracking of the cladding, thermal aging of neutron poisons, and atmospheric corrosion of canisters.

ST-Transportation addresses identified high priority technical issues associated with the retrieval and subsequent transportation of UNF. The focus of this work is on high burnup UNF ( $>45$ GWD/MTU) and includes field testing to assess realistic loading on fuel rods and assemblies during normal transport in order to obtain data to evaluate the integrity of UNF.

ST-Storage and Transportation Engineering Analysis conducts analyses, integrates experimental data, and develops the technical basis for extended long-term storage and subsequent transportation of used fuel.

ST-Security assesses the impact of the used fuel standard over long storage periods, as well as how material attractiveness issues affect physical protection strategies and requirements.

DR-Thermal Load Management and Design Concepts refines mined geologic disposal concepts for UNF and high-level radioactive waste, using published information, international experience, and original analysis. Both "enclosed" (i.e., backfilled during operations) and "open" (i.e., ventilated during operations) reference disposal concepts will be identified and evaluated.

DR-Generic Engineered Barrier System Evaluations focuses on the identification and evaluation of important features and processes in the analysis of EBS design concepts and related materials for nuclear waste disposal in various types of repository environments in the near- field environment of disposal.

DR-Generic Natural System Evaluations develops experimental and computational capabilities for evaluating far-field environments of disposal and performs modeling analyses to support the development of disposal concepts in various geologic media (e.g., mined repositories in clay/shale, granitic rocks, and salt, and deep boreholes). This work includes, for example, the development of a geology and siting database.

DR-Generic Disposal System Level Modeling develops the necessary system models and computational framework to meet the evolving needs of the DOE NE and UFDC missions.

DR-Inventory provides estimates of types and quantities of primary and secondary waste streams from potential alternative fuel cycles.

DR-Low Level Radioactive Waste Disposition evaluates low-level radioactive waste disposal options to ensure that low-level radioactive waste that would be generated from potential future advanced fuel cycles can be disposed of safely and in a cost-effective manner.

DR-Deep Borehole Disposal advances the technical basis needed to evaluate the viability of this disposal concept and make progress towards implementing a fullscale demonstration.

DR-Salt $R \boldsymbol{\&} \boldsymbol{D}$ advances generic salt repository science and includes compiling and assessing the multiple data sources into a comprehensive salt testing database.

\section{USED FUEL DISPOSITION CAMPAIGN GOALS}

The UFDC has developed formal goals for near-term (i.e., fiscal year 2013-2015) and long-term (fiscal year 2015-2025) activities.

Near-Term--2013 through 2015: The focus during this period is on the development of science-based tools for evaluating storage, transportation, and disposal system performance using theory, experiments, and modeling. The tools will aim at understanding the fundamental processes in a variety of disposal environments, relying on information and data currently existing in waste management programs in the U.S. and other nations. Improvements in storage and transportation systems for used LWR fuel will be explored and developed. Concepts will be developed for storing and transporting 
used fuels and waste generated from a range of advanced fuel cycles.

Storage \& Transportation Near-Term Objectives:

- Develop a comprehensive plan for a demonstration storage platform (completed March 2012)

- Collaborate with industry to select one storage demonstration system

- Conduct material property testing on high burnup used fuel cladding in a hot cell

- Conduct corrosion laboratory studies on stainless steel storage canisters and continue industry collaboration to obtain in-situ data on storage canisters

- Develop advanced in-situ inspection techniques to monitor long-term behavior of storage safety components

- Identify and develop criteria for verification of fuel integrity prior to shipment after long-term storage.

- Develop advanced analytical approaches that can be applied to safety and security scenarios for storage

- Develop Aging Management Plans to support relicensing, extended storage, retrieval, and transportation

- Develop uncertainty quantification methods to support the technical basis for storage and transportation

- Conduct field testing of simulated used fuel in transportation environments to assess fuel robustness

- Develop a technical basis for licensing transportation systems designed to transport high burnup fuels

Disposal Research \& Crosscutting Near-Term Objectives:

- Develop parameter uncertainty ranges for repository design concepts, thermal characteristics for engineered and natural materials (properties, temperature limits), and characteristics of the advanced waste streams selected for analysis (inventory, waste forms)

- Develop descriptions of repository surface facilities and other repository infrastructure for each reference design concept

- Develop refined estimates of disposal system costs including repository surface facilities, for all reference design concepts

- Evaluate coupled thermal, mechanical, and hydrological processes to support the assessment of longterm performance of reference design concepts

- Develop field testing and site characterization techniques for future site characterization activities

- Develop a framework of computational models, with its appropriateness supported by experiments as appropriate, for evaluating disposal system performance for multiple disposal concepts

- Develop a catalog of potential disposal systems available in the US, with generic reference cases
- Compile current geologic and geographic data to with its appropriateness support site screening and selection activities

- Use disposal performance modeling capability to prioritize the disposal $R \& D$ program

- Support fuel cycle options analyses using both storage/transportation/disposal interface and disposal performance modeling tools to help guide R\&D for a range of alternative future fuel cycles

Long-Term--2015 through 2025: The focus during this period is primarily on continued development of the capability for understanding of disposal system performance through modeling and simulation and focused experimentation in the laboratory and field (i.e. underground research laboratories [URLs]). The URLs used will either be existing or constructed in the US or those that can be accessed through international collaborations (for example, Japanese, Korean, and European URLs), or a combination thereof. Storage and transportation concepts for used fuel and wastes for an advanced fuel cycle will be selected and regulatory approval of these concepts will be initiated.

Storage \& Transportation Long-Term Objectives:

- Collaborate with industry to field a full-scale NRClicensed demonstration storage $\mathrm{R} \& \mathrm{D}$ program with monitoring/inspection capabilities to assess longterm performance

- Validate advanced analytical approaches for evaluating storage options based on the five-year recommendations

- Complete the technical basis for licensing transportation systems designed to ship high burnup fuels

Disposal Research Long-Term Objectives:

- Support the development and implementation of integrated storage, transportation, and disposal concepts compatible with utility operational practices and timely underground emplacement of waste

- Develop advanced modeling capability for evaluating and demonstrating disposal system performance, confirmed by experiments.

- Conduct experimental programs to fill data needs and confirm advanced modeling approaches

- Continue to develop enhancements of disposal concepts, to achieve safe disposal while facilitating earlier, less costly, and more efficient emplacement of hotter waste with fewer intermediate handling and processing steps.

- Use disposal system and subsystem modeling and experimental work to provide robust support for the selection of geologic disposal options and subsequent siting and licensing applications. 


\section{NUCLEAR FUELS STORAGE AND TRANSPORTATION PLANNING PROJECT}

The DOE Office of Nuclear Energy has established the Nuclear Fuels Storage and Transportation (NFST) Planning Project to plan for and implement the storage and transportation aspects of the Administration's Strategy for the Management and Disposal of Used Nuclear Fuel and High-Level Radioactive Waste [3].

The DOE plans to implement a program (with the appropriate authorizations from Congress) that contains the following milestones [3] :

- 2021 - site, design and license, construct, and begin operations of a pilot interim storage facility (ISF) with an initial focus on accepting used nuclear fuel from shutdown reactor sites

- 2025 - site and license a larger ISF with sufficient capacity to provide flexibility in the waste management system and allow for acceptance of enough used nuclear fuel to reduce expected government liabilities

- 2048 - make demonstrable progress on the siting and characterization of repository sites to facilitate the availability of a geologic repository

The NFST Planning Project activities are aligned with the key principles that underpin the BRC recommendations [2]. They are conducted by the DOE Office of Nuclear Energy under existing authority, and prioritized and executed such that they can provide a foundation for a new nuclear waste management organization.

The objective of the NFST Planning Project is to develop and begin implementation of an integrated management plan to (1) implement interim storage; (2) improve the overall integration of storage as a planned part of the waste management system; and (3) prepare for the large-scale transportation of used nuclear fuel and high-level waste, with an initial focus on removing used nuclear fuel from shutdown reactor sites in the U.S.

\section{CONCLUSIONS}

Working under the direction of the DOE Office of Nuclear Energy, the UFDC is conducting a broad range of R\&D activities at multiple US National Laboratories to support the safe and secure storage, transportation, and permanent disposal of used nuclear fuel and highlevel radioactive wastes derived from the existing and future nuclear fuel cycles. R\&D activities focus on both near term goals, such as collaborating with industry to develop data that will support improved understanding of processes relevant to the extended storage of existing UNF, and long-term goals, such as supporting the implementation of integrated storage, transportation, and disposal systems.

\section{ACKNOWLEDGMENTS}

Sandia National Laboratories is a multi-program laboratory managed and operated by Sandia Corporation, a wholly owned subsidiary of Lockheed Martin Corporation, for the United States Department of Energy's National Nuclear Security Administration under contract DE-AC04-94AL85000. Lawrence Berkeley National Laboratory is operated for the United States Department of Energy by the University of California under contract DE-AC02-05CH11231. Argonne National Laboratory is a United States Department of Energy Office of Science laboratory, operated by University of Chicago Argonne, LLC, under contract DE-AC02$06 \mathrm{CH} 11357$.

SAND 2013-4957C Approved for unlimited release.

\section{REFERENCES}

[1] DOE (United States Department of Energy). Nuclear Energy Research and Development Roadmap Report to Congress, DOE Office of Nuclear Energy, http://www.ne.doe.gov/doclibrary/overview.html (2010)

[2] BRC (Blue Ribbon Commission on America's Nuclear Future). Report to the Secretary of Energy, January 2012. http://cybercemetery.unt.edu/archivel brc/2012062 0211605/http:/brc.gov/ (2012)

[3] DOE (United States Department of Energy). Strategy for the Management and Disposal of Used Nuclear Fuel and High -Level Radioactive Waste, http://energy.gov/ downloads/strategy-management-and-disposal-used- nuclear-fuel-and-high-level-radioactivewaste (2013)

[4] Used Fuel Disposition Campaign. Used Nuclear Fuel Storage and Transportation Data Gap Prioritization, FCRD-USED-2012-000109 (2012) 